\title{
Advanced Hybrid Propulsion and Energy Management System for High Efficiency, Off Highway, 240 Ton Class, Diesel Electric Haul Trucks
}

Principal Investigator: Tim Richter

GE Global Research, 1 Research Circle, EP110C, Niskayuna, NY 12309

(518) 387-5670; fax: (518) 387-6675; e-mail: tim.richter@ge.com

Technology Development Area Specialist: Lee Slezak

(202) 586-2335; fax: (202) 586-1610; e-mail: lee.slezak@ee.doe.gov

Field Project Manager: Chris Johnson

(304) 285-4718; fax: (304) 285-4403; e-mail: Christopher.Johnson@or.netl.doe.gov

Key Participants

Tim Richter, GE Global Research

Henry Young, GE Transportation

Dan Funcannon, Komatsu America Corp.

Contractor: GE Global Research

Contract No.: DE-FC04-2002AL68080

\section{Objective}

The objective of this project is to reduce the fuel consumption of off-highway vehicles, specifically large tonnage mine haul trucks. A hybrid energy storage and management system will be added to a conventional diesel-electric truck that will allow capture of braking energy normally dissipated in grid resistors as heat. The captured energy will be used during acceleration and motoring, reducing the diesel engine load, thus conserving fuel.

\section{Approach}

The project will work towards a system validation of the hybrid system by first selecting an energy storage subsystem and energy management subsystem. Laboratory testing at a subscale level will evaluate these selections and then a full-scale laboratory test will be performed. After the subsystems have been proven at the full-scale lab, equipment will be mounted on a mine haul truck and integrated with the vehicle systems. The integrated hybrid components will be exercised to show functionality, capability, and fuel economy impacts in a mine setting.

\section{Project Accomplishments}

- Subscale (100hp) demonstration of hybrid concept, 2003

- System modeling and design specifications, 2004

- Full-scale system test equipment construction, 2005

- Truck demonstration hardware design complete, 2005

- Full-scale system test, 2006

- Full hybrid component integration, 2007

- Full-scale hybrid demonstration, 2008

- Battery cell testing, 2008 


\section{Introduction}

Off-highway vehicles, also known as mine haul trucks or OHVs, are used in open-pit mining operations for material movement. They are typically loaded with shovels, excavators or wheel loaders and transport ore or waste products to crushers, stockpiles, and waste areas. During normal operation, an OHV can burn over 50 gallons of fuel per hour. For a mine running several dozen trucks in 24/7 operations, even modest fuel savings can create significant opportunity for a hybrid system to provide value.

The conventional mine haul truck, uses a diesel engine to turn an alternator that generates alternating current (AC) electricity. The electricity is rectified to direct current (DC) electricity that is applied to the main electrical bus called the DC Link. Power electronics convert the DC link voltage to variable frequency, 3phase AC that drives the wheel motors during motoring. When braking is required, the wheel motors function as generators and electrical power is directed to the Braking Grid Resistors, also known as the "Grid Box," to be dissipated as heat.

Figure 1 shows a block diagram of the hybrid vehicle system. The prototype truck will be modified from a conventional diesel-electric OHV to contain hybrid components, each playing a specific role in the recovery and reuse of braking energy. The primary components added to the conventional OHV are the Hybrid Vehicle System Controls (HSC), Energy Management System (EMS), and Energy Storage System (ESS). The Hybrid Vehicle System Controls perform the high-level supervisory functions of the hybrid vehicle, primarily controlling the balance of engine power, grid dissipation and battery charging or discharging. Performing these functions requires intimate connections to all of the truck systems. The Energy Management System (EMS) acts to convert electrical power on the DC link into levels compatible with the ESS. The EMS is essentially a high power DC-DC converter. The ESS consists of the batteries and manual disconnects, fuses and related safety and protective components.

The hybrid controls will provide two operational modes: fuel saving mode and performance mode. In fuel saving mode, the truck reduces diesel power when power is supplied from the hybrid system such that maximum power is the same as the conventional truck power. This results in a displacement of diesel fuel with battery power for fuel savings. In performance mode, full diesel power is supplemented with battery power. This provides improved productivity.

These modes are tested on an OHV retrofitted with these hybrid components at Komatsu Proving Grounds near Tucson, Arizona. The Proving Grounds are situated in an inactive copper mine so mine roads are available that represent actual mine conditions. Many of the haul roads are maintained and provide a representative testing facility for the project. Two primary roads are used for testing, shown in Figure 2 as the "mine haul road" and " $10 \%$ grade".

\section{System Requirements \& Modeling}

The first phase of the hybrid OHV project targeted understanding haul cycle performance of existing haul trucks and relating this understanding to a predictive model that would assist in system design. The project team traveled to the Komatsu Proving Grounds to run performance tests and to collect spatial information from a Komatsu 930E haul truck. The performance data was logged using the GE propulsion control system on several trial cycles on the mine haul road.

A simulation model was developed using Matlab/Simulink. This model has the capability to simulate actual haul grades and representative grades for various trucks and hybrid configurations. Script functions simplify the analysis of swept variable inputs enabling the graphs and performance surfaces to be plotted to gain understanding of the impacts of different inputs and system configurations. Data from the 930E trials was utilized to provide preliminary validation of the Matlab/Simulink model.

The performance criteria that are used to evaluate the system are productivity (tons/hour) and cost (\$/ton). These two metrics are needed to capture different mining operations. A specific example of this was the recent high demand for iron ore that drives mining operations to a maximum productivity mode. Cost becomes less 
important because pricing margins are high. Conversely, a low demand for iron ore moves mining operations towards cost sensitivity and production efficiency. Additionally, within each mine, waste haulage, low grade and high-grade ore haulage may require different optimization functions.

One consideration for modeling is the additional hybrid system weight. Although the truck is massive, weighing about 190 tons, the hybrid system that is required for such a large truck is also going to have significant mass. The gross vehicle weight is dictated by the tire capability so any additional weight from hybrid components means a reduction in payload capability. Recalling the performance criteria above, both are impacted by payload directly and significantly. The system model provides the capability to show the impacts of hybrid weight to both productivity and cost metrics.

\section{System Design}

With a predictive model created and validated for the mine haul road and $10 \%$ grade cycles on the $930 \mathrm{E}$ truck; the model was used to investigate the design space for the hybrid system. The model is a forward-facing power flow model that first calculates maximum capability of all elements of the truck respecting component constraints and stress limits. The model then evaluates the required tractive effort command needed to produce desired truck motion and executes this command within the calculated constraints and limits. The resulting output gives visibility into the system performance down to the component level.

This modeling effort first showed the impacts of hybrid mass on productivity and established using $0 \%$ productivity change as a constraint in hybrid operational modes analysis. Recall that a pure fuel savings mode will result in the truck performing the exact same drive cycle (velocity vs. time traces), however because of the reduced payload, productivity is lower than the baseline. By adding some hybrid boost to the uphill haul segment, productivity can be regained to equivalence with the baseline at the expense of reducing fuel savings benefits.

The preferred means of looking at this behavior was to add designed experiments functionality to the model where component specifications or operational variables can be swept across a design space to create plots or surfaces that are used to find optimal charging and discharging operating points and hybrid system capacity to maximize productivity and/or cost. This approach allowed visualization of the hybrid vehicle performance and enhanced the team's understanding of the complex interactions present in the system.

With regard to energy storage concerns, operating specifications such as temperature, vibration and weight have significant impacts on the design and component requirements. Of major consideration in the hybrid design was the selection of energy storage components. The leading candidates for storage are electrochemical (battery) and kinetic (flywheel). Based on knowledge and experience from other projects, the flywheel was removed from consideration. The reliability and safety of a flywheel system large enough to accommodate the regenerative energy on a mobile platform was not proven or available in current product offerings.

Consideration for battery technology warranted a detailed investigation into the performance capabilities, environmental specifications and pricing for the various chemistries. All battery types were considered: nickel cadmium (NiCd), nickel metal hydride (NiMH), lithium (Li-Ion, Li-polymer) and sodium nickel chloride $\left(\mathrm{NaNiCl}_{2}\right)$. Key selection criteria were energy density and environmental capability.

On energy density, the Li-Ion is the highest performing battery with $\mathrm{NaNiCl}_{2}$ a close second. It should be made clear that the project team took care to make sure the various chemistries were compared on equal merits; that is at the battery pack level and not at the cell level. When comparing technologies on environmental aspects, the $\mathrm{NaNiCl}_{2}$ battery is the clear choice for heavy-duty applications such as the hybrid $\mathrm{OHV}$. The $\mathrm{NaNiCl}_{2}$ battery operates with a cell temperature at about $300^{\circ} \mathrm{C}$ and uses air-cooling to remove excess heat generated by resistive losses during charge and discharge. This high temperature design lets the battery operate with effectively no limit on ambient temperatures. The OHV ambient temperature specification is $55^{\circ} \mathrm{C}$, well within the range of acceptability for $\mathrm{NaNiCl}_{2}$ batteries. 
The other nickel and lithium batteries do not have such high operational temperatures. These technologies can be pushed towards $50^{\circ} \mathrm{C}$ as a maximum operating temperature, but at increasingly derated power above around $35^{\circ} \mathrm{C}$. Operating these cell chemistries above approximately $35^{\circ} \mathrm{C}$ will accelerate aging processes potentially reducing the life of the battery significantly. The cell temperature specifications are generally noted for internal cell temperatures, not battery pack case temperatures where cooling is convenient. Including allocations for temperature differentials across the thermal path makes it obvious that a need for an active cooling system is required for the use of the non-sodium chemistries. The team did consider active cooling, but cooling systems were not economically available to meet the harsh vibration and life requirement for high vibration OHV applications.

The team selected the sodium nickel chloride chemistry as the battery of choice for the prototype demonstration. This same conclusion was made for the related DOE Hybrid Locomotive project. Since this selection, GE has demonstrated the sodium battery on both OHV and locomotive. Today, GE is continuing focused development on advanced sodium battery technology for heavy hybrid and other applications.

ESS designs for the hybrid OHV were drafted and compared using the OHV model. The first design consisted of two energy storage component types, a sodium battery and a NiCd battery pack. The expectation was that GE's extensive experience in NiCd would reduce risk of the lesser-known $\mathrm{NaNiCl}_{2}$ battery. Primarily limited by size and cost, a hybrid system of approximately $500 \mathrm{~kW}$ was proposed. Initial modeling showed energy savings of up to $15 \%$ with equivalent productivity.

\section{Subscale Testing}

The $\mathrm{NaNiCl}_{2}$ battery selected was manufactured by MES-DEA in Switzerland for use in electric vehicles. The battery was installed in several applications such as transit buses and automobiles, but a significant history of performance and life data, particularly specific for heavy-duty hybrids was not available. Therefore, there was a need to perform testing on cells.

A subscale test facility was constructed to test batteries in a hardware-in-the-loop apparatus capable of simulating a subscale truck system for both $\mathrm{NiCd}$ and $\mathrm{NaNiCl}_{2}$ cells. Testing by this facility demonstrated that energy management of the two systems met the $\mathrm{OHV}$ requirements and cell performance was acceptable, however life tests were not readily achieved with this apparatus.

Life testing was pursued separately. Before describing the life testing, it is important to formally declare the means for determining end of life for the OHV application. Traditionally, the end of life of a battery is when less than $80 \%$ of the original capacity of the battery is actively available. For OHV applications, specifically with $\mathrm{NaNiCl}_{2}$ batteries, resistance rise is the critical metric. As the cells degrade, it becomes harder (higher resistance) to charge them. Because the $\mathrm{OHV}$ is a power-centric application, this resistance rise will begin to lessen the amount of regenerative energy captured, thus lowering fuel savings.

To address life concerns, MES-DEA performed two life tests specific to a single battery solution of their $\mathrm{NaNiCl}_{2}$ cells. The MES-DEA test was performed using a 10-cell test apparatus with 10 cells connected in series and immersed in a temperature-controlled environment. The cells were repeatedly cycled on a haul route generated using the OHV model and data from the Komatsu Proving Ground mine haul road testing. The first test started was designed using the nameplate ratings for the battery. The MES-DEA testing supported the manufacturer's 1000 nameplate life expectancy and greatly increased understanding of how the battery would operate for the demonstration. Additionally, MES-DEA ran a second test to evaluate life for application cycles with charge powers above the nameplate rating. This test was designed to explore how hard the battery could be pushed to validate the certainty of the nameplate ratings. The life test was stopped after only about 400 nameplate cycles and supported that the nameplate rating of the battery was appropriate.

\section{Demonstration System Design}

With a better understanding of battery capability and life, the project team decided to implement a single battery solution with the $\mathrm{NaNiCl}_{2}$ battery for the demonstration prototype. This was driven by the life test 
results of cells on nameplate rated cycles and successes in the related US Department of Energy Hybrid Locomotive project. Reducing to a single battery chemistry also simplified the power electronics and energy management algorithms. A final design of twelve (12) $\mathrm{Z} 12 \mathrm{NaNiCl}_{2}$ batteries was selected to give reasonable fuel savings ( $\sim \%$ ) within the budget of the project. The primary reason for the reduction in fuel savings projection from the initial $15 \%$ is the refinement of both the truck system model and battery resistance models. Twelve batteries also fit well in deck-mounted and front bumper-mounted enclosures. Before construction of the enclosures and support systems, several key areas of interest needed to be explored.

Originally, a 930E hybrid truck was envisioned for the demonstration. Based on production schedules and truck availability, an $830 \mathrm{E}$ truck was chosen for the demonstration. The $830 \mathrm{E}$ is capable of 240 ton payload while the 930E can haul 320 ton payloads. Both trucks share a series electric drive with AC wheel motors. The method of hybridization is the same for both trucks and a successful 830E hybrid prototype indicates likely success at $930 \mathrm{E}$ hybridization efforts.

A substantial amount of effort was spent discussing mounting options, locations and enclosure sizes with Komatsu. Concerns over operator visibility, vehicle dynamics, and truck modifications were discussed. Two structural frames and enclosures were designed to accommodate eight (8) Z12 batteries on a deck-mounted enclosure and (4) Z12 batteries on a front bumper-mounted enclosure. Each enclosure would have protective and monitoring circuits, cooling capability and robust protection from environmental conditions. A final detail of the location of components for the hybrid OHV is shown in Figure 4.

It is well known that OHVs have high levels of frame-borne vibration from the engine and rolling tires. To ensure the batteries are protected against harmful vibrations, an analysis was carried out to study the frame stiffness, input vibration spectrum, transmission of vibration energy. The Z5 battery, also from MES-DEA has been tested using the USABC testing procedure. The Z5 is $1 / 2$ of the Z12 and shares the same construction as the Z12. The Z5 was successfully tested to the USABC vibration spectrum and served as a baseline capability for this analysis. Based on the vibration analysis, it was found the low-frequency energy would be the biggest concern and vibration isolation would be needed. A vibration isolation system was designed and incorporated into the battery enclosure frame design.

\section{Full scale Testing \& Design}

The project team had successfully demonstrated subscale hardware in the loop test apparatus to explore the feasibility of the system and to validate performance of the design. A much more complicated undertaking is to integrate a fully functional hybrid system with a production truck control system. For this effort, it was necessary to make a full-scale system integrated with GE Transportation's production test facilities. GE Transportation maintains a full-scale motor-generator set that has capability to simulate the wheel motors on the $\mathrm{OHV}$ for any load and grade conditions. A modified control group, batteries, and support components were assembled at GE Transportation, as shown in Figure 3.

The primary reason for the full-scale prototype was for development of hybrid control algorithms and the interface with the conventional control hardware. The full-scale prototype afforded software and hardware engineers a platform to develop \& test algorithms in a controlled test environment close to any experts that may be required for consultation. In 2006, the GE Transportation team was successful in operating the system at full power both in performance and fuel saving modes.

\section{System Validation Demonstration}

The hybrid system can operate in three modes: baseline, fuel saving, and performance. The baseline mode simply disables the hybrid system. The fuel saving mode uses the diesel engine and hybrid power to provide rated power to the wheels; this mode results in fuel savings as the engine providing less than rated power, however productivity is reduced because of the hybrid weight overhead. The performance mode utilizes full engine power supplemented with hybrid power for extra speed on grade, increasing productivity. This mode can simultaneously realize fuel savings as the engine is running for less time during uphill hauls. Ultimately, a 
hybrid OHV would operate in a blended mode depending on the mine operation's priority between increased productions vs. reduced costs.

An example result from testing of the hybrid OHV is shown in Figure 5. This graph shows the truck climbing a 10\% grade turning around at the top of the hill and returning to the start line. The green trace shows the hybrid power, positive for battery discharge or motoring support. During the downhill, charging is stopped when the required energy is recovered, maintaining $0 \%$ delta SOC over the haul cycle. This is required to ensure the system is not operated in a charge accumulation or charge depletion mode, as it must be a sustainable hybrid cycle. Direct fuel measurements on the OHV were difficult to obtain due to insufficient instrumentation sensitivities on fuel metering equipment. Overall fuel burn observations support the $5 \%$ model prediction and gave confidence that hybrid can indeed reduce fuel consumption.

The operational hybrid off-highway vehicle was presented to U.S. Department of Energy staff in January 2008, shown in Figure 6. A joint team from GE and Komatsu was present to show first hand the operation of the mining truck in conventional operation and with the hybrid system operating. Loading and tipping demonstrations were also shown, illustrating the shock loads and harsh environment that the system must operate in. The demonstrations were carried out with no system failures.

\section{Battery Testing}

A key aspect to moving the hybrid demonstration technology into commercialization is in understanding the battery performance and life expectancy. Life characteristics of batteries, regardless of chemistry, are dependent on the hybrid cycle, environmental factors and manufacturing quality. The final segment of this project investigated, at a preliminary level, the behavior of GE advanced sodium chemistry cells tested with OHV hybrid cycles.

The first step for the team was to determine a representative cycle for testing. Many haul cycles were analyzed using the OHV model developed earlier in this project. The analysis generated battery current waveforms for each cycle. These two cycles were combined serially to produce a composite test cycle (CTC) that could be run on the ABC150 battery test apparatus.

The first test used previously tested cells from the locomotive program to accelerate the start of testing and validation of testing algorithms specific to the hybrid OHV and the CTC. The first experiment applied the CTC current as close to the top of charge as possible. Because the sodium cells are more energy dense than power dense, the hybrid cycle utilizes only about 5-10\% of the nameplate Ah per cycle. The hypothesis is to utilize the lowest charge resistance material near the top of charge.

During this first test, it was found that high charge rates at the top of charge work for only a limited time as resistance during charge builds up quickly. This behavior is common in secondary cells, and was confirmed for the specific CTC currents and sodium cells as well. The first cells were also connected using high temperature insulated wire that proved to have higher resistance than the battery packs that utilize welded steel straps. The test equipment was validated to operate as expected and limit alarms were also tested successfully.

The second set of cells was hand built using the latest GE advanced sodium chemistry for the cathode. The set was installed in the test apparatus and connected using the same weld process and materials as in battery manufacturing. These cycles ran very well and showed no measurable degradation as measured by cell resistance during charge or discharge. The test ran for over 350 cycles which represents 700 haul cycles or about 15 days of haul truck operation. The test was stopped because the test resources were needed for another project for about two weeks. Prior to the test equipment changeover, the cells were fully charged to $100 \%$ SOC. The temperature of the cells was maintained during the stoppage.

Upon resuming testing, cell number six immediately began to exhibit unpredictable behavior. The cell would reach high cell voltages during charge, deviating from the other cells considerably. This cell ramped up its voltage very quickly near the end of the first charge cycle. The test cell string was still operable for small charge and discharge cycles, however the representative cycling could not continue, and the life testing was 
aborted. Unfortunately, the cause of the excessive deviation of cell 6 could not be pinned to a specific event as the two-week test stoppage did introduce a break in monitoring circuits and control.

After completion of the test, the cells were removed from the test apparatus and dissected to understand the failure modes and life impacts. Teardown of the test cells from the OHV project is expected to provide insight into the degradation modes of cells that are exposed to hybrid off-highway vehicle applications. This dissection and post-mortem analysis is being performed separate from the OHV project and results will not be documented in this report.

\section{Conclusions}

The operational demonstration of the hybrid off-highway vehicle validated a system design aimed at saving fuel and/or improving productivity of mine haul trucks. Continuing work is required to further develop battery technology and to better understand the aggregate benefits of hybrid technology as applied to mining customers and their greatly varied uses and operations.

The demonstration of hybrid vehicle technology on off-highway mining vehicles has generated interest from several organizations, especially in light of recent record high diesel fuel prices. GE is continuing to work through its GE Transportation business to explore paths towards commercialization of this technology. There are difficult hurdles to overcome, specifically, battery costs and life, and GE is committed to advancing battery technology that will support heavy-duty hybrid applications such as locomotive and OHV.

Mining companies are interested in hybrid vehicle applications as a means to reduce fuel consumption and lower operating costs. As battery technology advances and large format storage solutions become more mass produced and proven, the hybrid technology developed in this project may become accepted. In the meantime, the modeling work from this project has produced a predictive analysis toolkit that enables GE and their customers to understand the primary drivers and benefits for hybridization. 


\section{Acknowledgements}

This project was initially supported by the late Sid Diamond at the US Department of Energy. Without Sid's vision in hybrid vehicles, this project would likely not have happened. The continuing support of the US DOE from Lee Slezak and the DOE National Energy Technology Lab (NETL) helped us to complete the project with a successful demonstration.

Support from senior leadership in GE and Komatsu is also recognized through the support of Scott Donnelly, Senior Vice President of GE Global Research, Mark Little, Vice President of GE Global Research, Tina Donikowski, General Manager at GE Transportation, and Roland Sedziol, Business Program Manager at GE Global Research.

Special thanks to Kim Byard, Dan Funcannon, and Don Lindell at Komatsu America Corporation and Rich Tumblin and the staff at the Komatsu Proving Grounds for working closely with the GE team on mounting the test equipment and providing support at the Proving Grounds.

Thanks also to the GE Transportation team of Henry Young, Bertrand Bastien, and Tim Brown who worked endless hours developing control algorithms and hardware that brought the GRC modeling work to reality in the demonstration truck.

This project also had support from many others not named above. The project team would like to thank everyone that has supported the efforts culminating in demonstration of the "world's largest hybrid vehicle." 
Figures

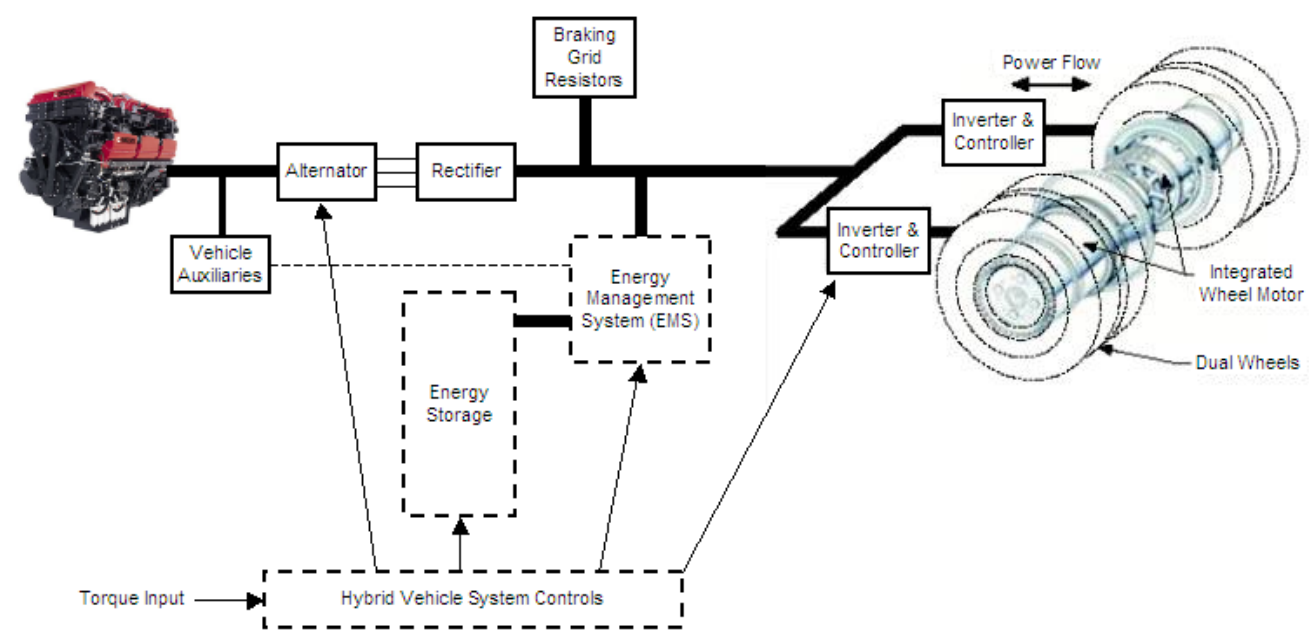

Figure 1 - Hybrid Electric System Block Diagram

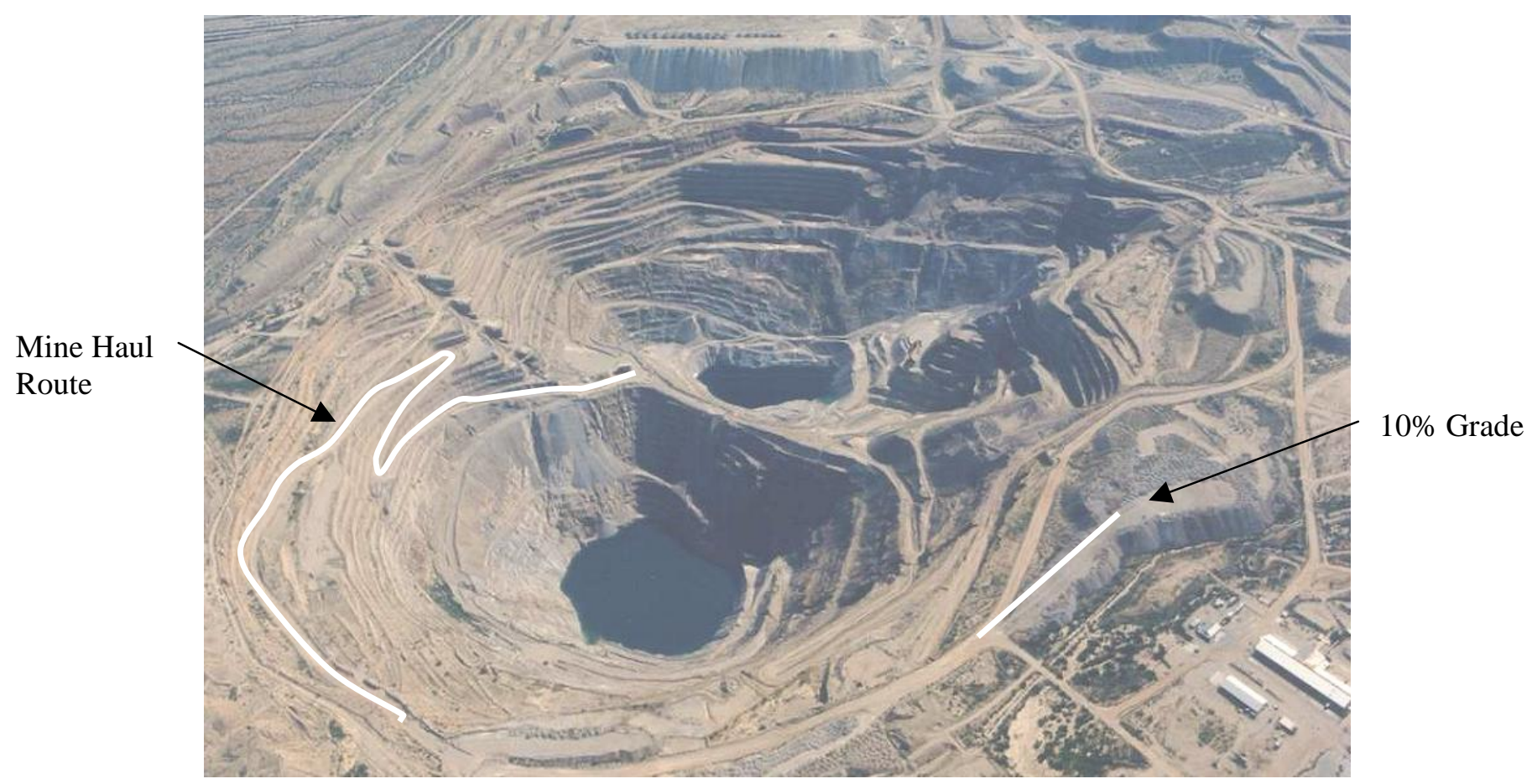

Figure 2 - Komatsu Proving Grounds, Green Valley, AZ 


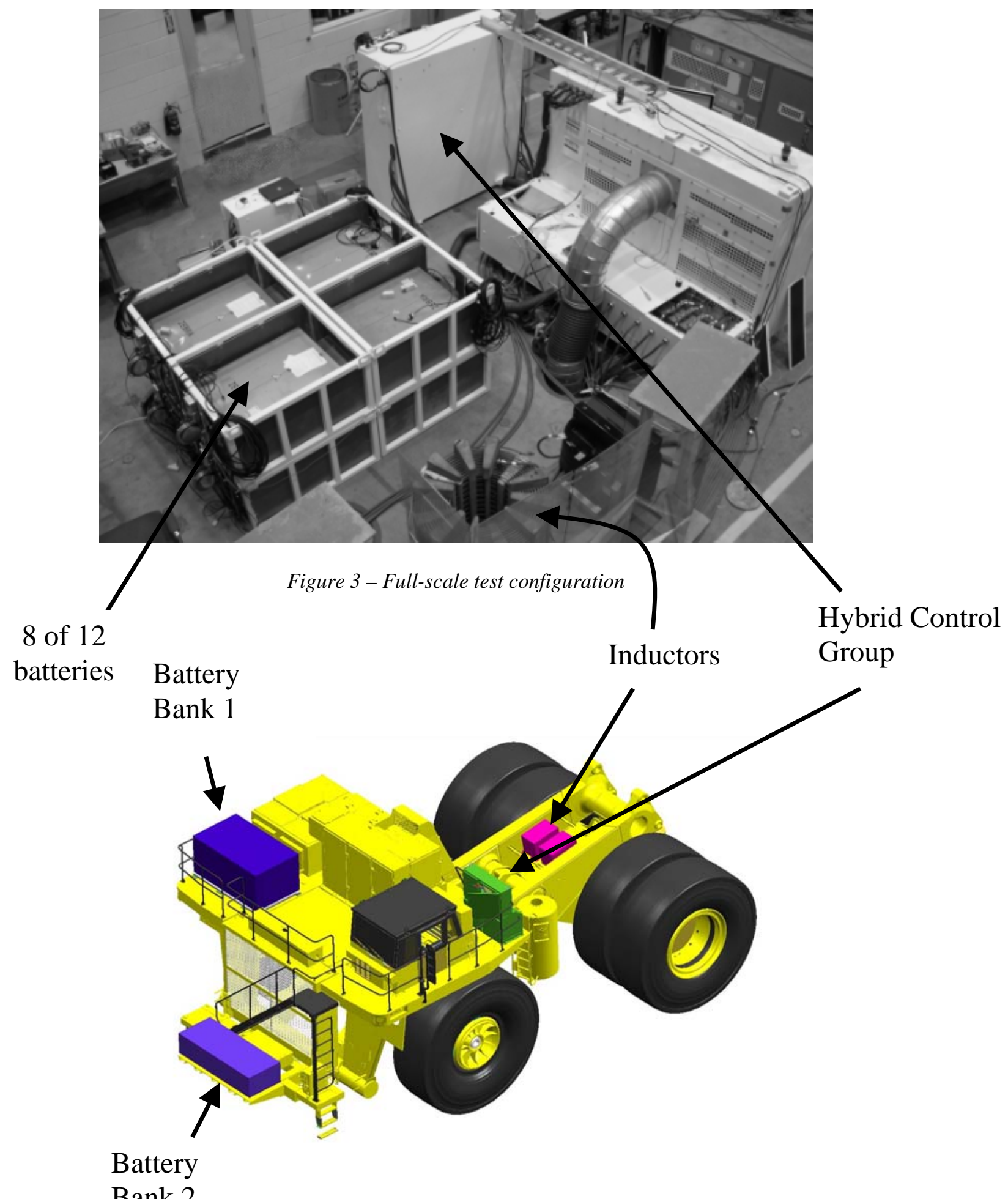

Figure 4 - Hybrid Equipment Groups 


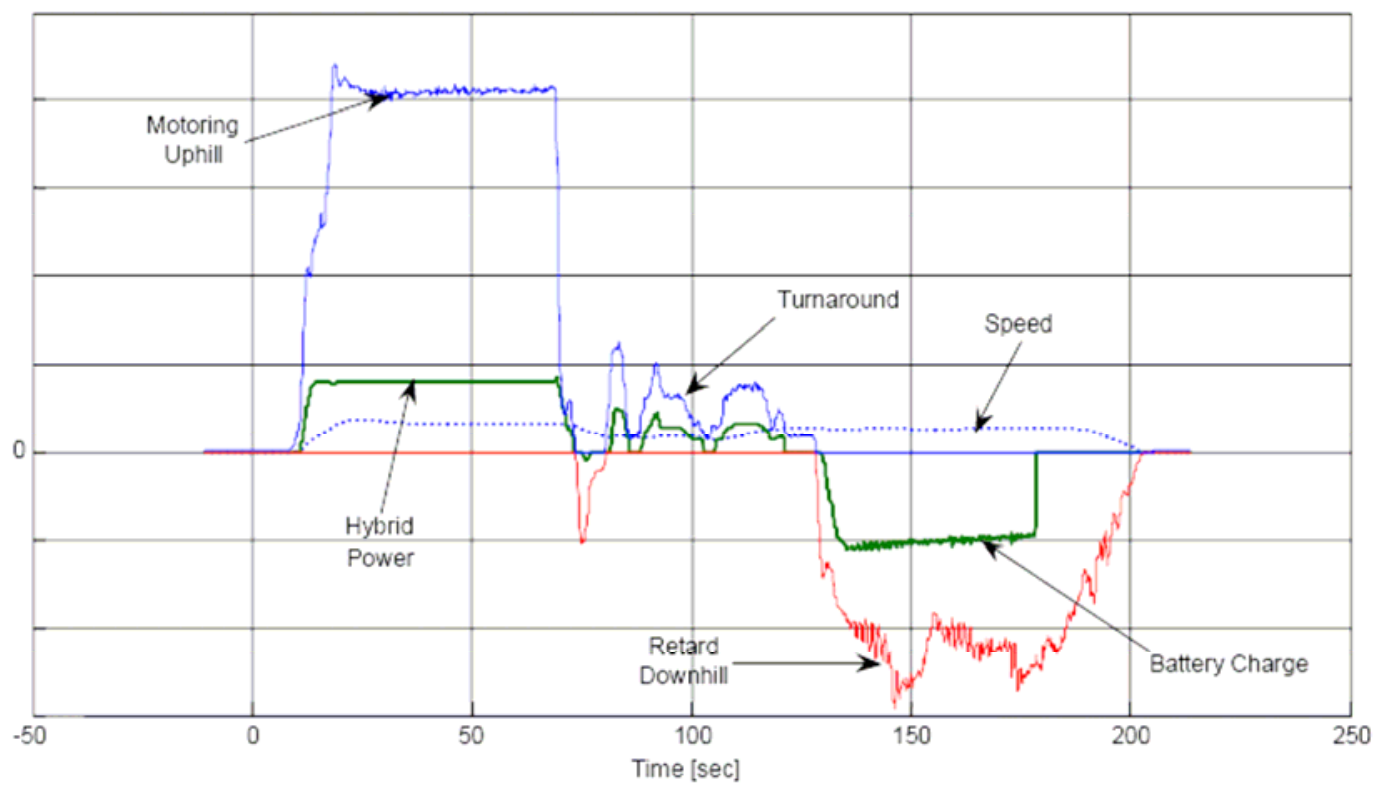

Figure 5-10\% Grade Hybrid Performance

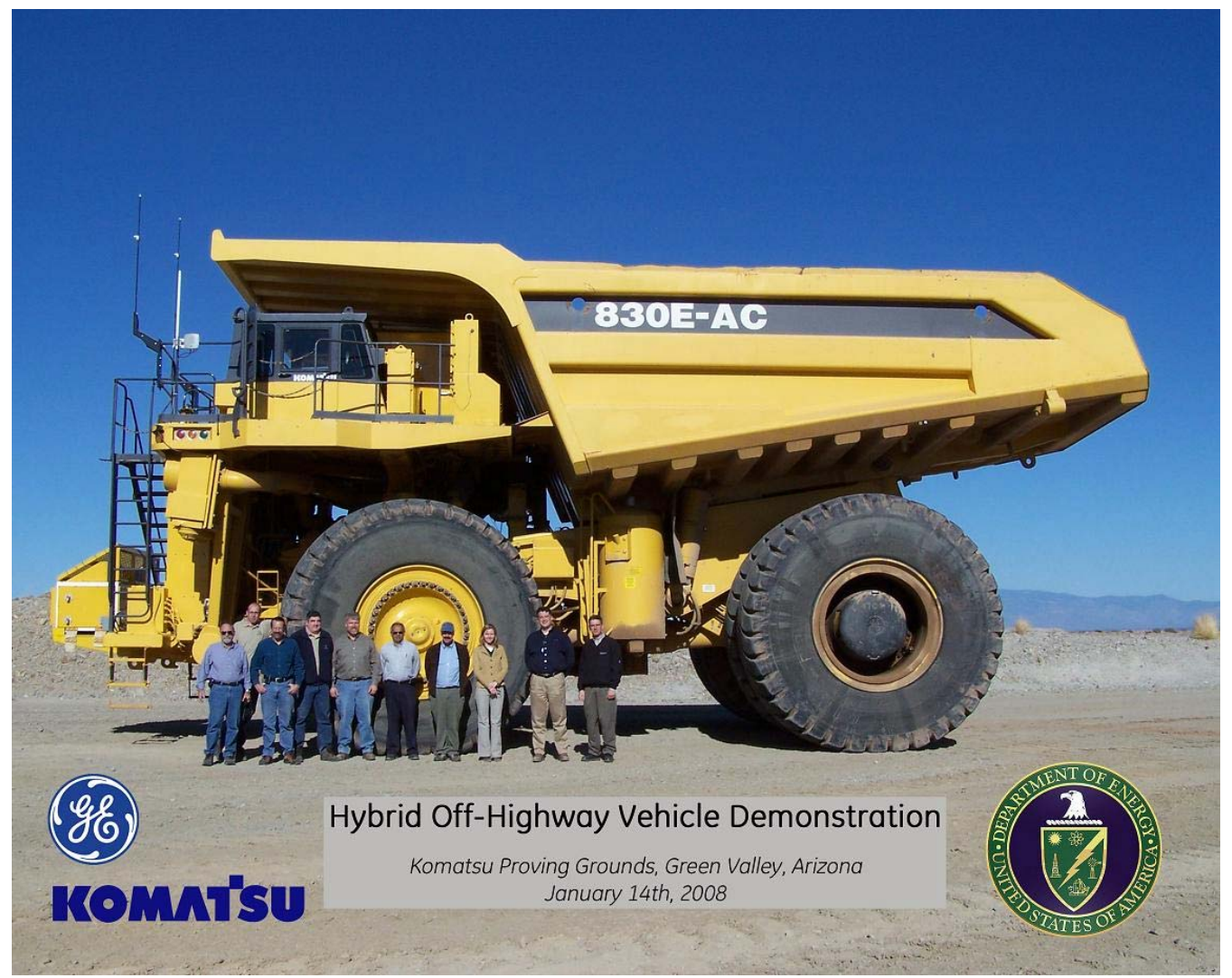

Figure 6 - US Department of Energy Demonstration 